\title{
Número de gerações de um percevejo e seu parasitoide e da severidade da ferrugem asiática em soja, simulados em cenários de clima e manejo no norte do RS
}

\author{
Number of generations of a stink bug and its parasitoid and severity of soybean rust, simulated \\ under climate and crop management scenarios in northern RS State, Brazil
}

\author{
Vanessa Vitória Chevarria ${ }^{\mathrm{I}^{*}}$ Emerson Medeiros Del Ponte $^{\mathrm{I}}$ Simone Mundstock Jahnke ${ }^{\mathrm{I}}$
}

RESUMO

\begin{abstract}
Objetivou-se simular o número de gerações do percevejo Euschistus heros e seu parasitoide Telenomus podisi e da severidade da ferrugem causada por Phakopsora pachyrhizi na cultura da soja em função da data de semeadura, cultivar e momento de ocorrência desses organismos. A simulação foi feita em dois locais representativos de duas importantes regiões produtoras de soja no Estado do Rio Grande do Sul. Modelos bioclimáticos dos insetos e da doença foram integrados a um modelo de simulação da cultura da soja (DSSAT) e rodados para uma série temporal de dados meteorológicos diários para Passo Fundo (52 anos) e Santa Rosa (34 anos). Independente do grupo de maturação, quanto mais antecipada foi a data da semeadura $e$ o estádio de ocorrência de $\boldsymbol{E}$. heros na cultura, maior o número de gerações (de 2 a 3) até a maturação fisiológica da soja. Para T. podisi, um maior número de gerações (5 a 6) foi simulado para semeadura antecipada e cultivares de ciclo tardio. Para a ferrugem asiática não foram observadas tendências de redução nos níveis médios de severidade com o uso de práticas preconizadas, como plantio antecipado e cultivares de grupos mais precoces de maturação.
\end{abstract}

Palavras-chave: Euschistus heros, Telenomus podisi, Phakopsora pachyrhizi, modelos bioclimáticos, Glycine max.

\section{ABSTRACT}

The objective of this study was to simulate the number of generations of a soybean insect pest (Euschistus heros) and its parasitoid (Telenomus podisi) and a fungal disease (soybean rust caused by Phakopsora pachyrhizi) as influenced by sowing date, cultivar and time of occurrence of the pest and the disease. Bioclimatic models that predict development of the organisms and severity of the disease were integrated into a crop simulation model of soybean (DSSAT) that predicted phenological stages of the crop for scenarios of sowing data and cultivar maturity group in a long time series of daily meteorological data to Passo Fundo and Santa Rosa, Rio Grande do Sul State, Brazil. The results showed that regardless of the maturity group, the earlier the sowing date and the time of occurrence of $\boldsymbol{E}$. heros in the field, the greater its number of generations (2 to 3) until physiological maturity. For T. podisi, a higher number of generations (5 to 6) was estimated for the earlier sowing dates and late-maturing cultivars. For soybean rust no significant trends of reduction in the mean disease severity was observed when advocated practices such as early sowing and early-maturing cultivars were used.

Key words: Euschistus heros, Telenomus podisi, Phakopsora pachyrhizi, DSSAT, Glycine max.

\section{INTRODUÇÃO}

A cultura da soja (Glycine max L.) teve um incremento significativo em produtividade e área plantada nas últimas décadas, levando o país ao posto de segundo maior produtor mundial (IBGE, 2010). No entanto, estresses bióticos, como o ataque de insetos-praga e patógenos em diversas fases do ciclo da cultura, têm levado a perdas econômicas (REUNIÃO, 2009). No período reprodutivo da cultura, pode ocorrer o ataque de percevejos sugadores de vagens e sementes, sendo Euschistus heros (F.) (Hemiptera: Pentatomidae) a mais abundante, predominando até o Brasil Central (PANIZZI \& NIVA, 1994). No Rio Grande do Sul, há registro da ocorrência dessa espécie em soja e outras plantas hospedeiras (MEDEIROS \& MEGIER, 2009). A intensidade dos danos causados por percevejos à soja está relacionada diretamente ao

IDepartamento de Fitossanidade, Faculdade de Agronomia, Universidade Federal do Rio Grande do Sul (UFRGS), 91540-000, Porto Alegre, RS, Brasil. E-mail: vanessachevarria@yahoo.com.br. *Autor para correspondência. 
tamanho da população da praga, estádio fenológico da cultura quando de sua ocorrência e temperatura ambiental (CORRÊAA-FERREIRA, 2005). A ferrugem asiática, causada pelo fungo Phakopsora pachyrhizi Sydow, pode causar danos severos como resultado do rápido amarelecimento e queda prematura de folhas, prejudicando a formação dos grãos (YORINORI et al., 2005). No manejo integrado de pragas (MIPsoja), as tomadas de decisão levam em conta informações sobre os insetos-praga e sua densidade populacional, a ocorrência de inimigos naturais, bem como na capacidade da cultura de tolerar os danos (HOFFMANN-CAMPO et al., 2000). Nesse contexto, os percevejos podem ser controlados por parasitoides de ovos, como Telenomus podisi (Hymenoptera: Platygastridae) (CORRÊA-FERREIRA, 2002), o qual é encontrado com frequência nos levantamentos (PANIZZI et al., 1999), parasitando preferencialmente E. heros em hospedeiros alternativos na entressafra (DOETZER \& FOESTER, 2007). O clima tem influência decisiva na atividade biológica de pragas, sendo que, para os insetos, a temperatura é o fator chave, pois esses se desenvolvem e acumulam energia a partir de um limite térmico inferior, sendo assim possível a previsão do tempo de desenvolvimento das populações (CIVIDANES \& PARRA, 1994). Entretanto, são escassas as informações sobre influência de fatores climáticos em condições de campo para as pragas da soja e seus inimigos naturais. A ferrugem da soja, em particular, pode ocorrer em qualquer estádio da cultura, porém, relatos no Brasil, em condições naturais de epidemia, têm mostrado que a doença é mais comumente detectada no estádio reprodutivo, principalmente a partir do estádio de enchimento de grãos. No sul do Brasil, o impacto da doença na produtividade tem sido variável em função da variabilidade climática, especialmente da precipitação sazonal, que influencia nos níveis finais de severidade (DEL PONTE et al., 2011).

Nadisponibilidadedemodelos de simulação e predição de ocorrência e/ou o desenvolvimento de pragas e doenças de plantas, a avaliação de risco pode ser feita para diferentes cenários simulados de manejo ou clima futuro (SAVARY et al., 2011), além de aplicações em tempo real para orientar a tomada de decisão tática no manejo (ROSSI et al., 2010). A maioria dos modelos de pragas e doenças são do tipo climáticos, uma vez que consideram a influência de condições meteorológicas sobre as fases do ciclo de vida dos organismos (STINNER et al., 1975). Estudos de impacto com cenários históricos de clima são importantes para caracterizar o risco médio e sua variabilidade interanual (DEL PONTE et al., 2011). A maioria desses utiliza apenas a informação do clima sobre a praga, sem levar em conta o desenvolvimento da cultura, cujo momento dos estádios fenológicos e a produtividade variam a cada ano em função da data de plantio e grupo de maturação e condições meteorológicas durante a safra. Programas mais complexos integram os modelos de pragas em modelos de simulação de culturas, por meio de um mecanismo de dano que penaliza a produtividade, o que é considerado um acoplamento verdadeiro do modelo (BATCHELOR et al., 1993). De outra forma, a integração pode envolver o uso do modelo de predição de praga/doença a partir de uma informação gerada pelo simulador da cultura, quando o interesse é simular a intensidade de ataque ou desenvolvimento, a partir, por exemplo, de um determinado momento ou estádio fenológico para uma determinada data de plantio (DEL PONTE et al., 2009). Assim, simula-se com maior realismo, considerando o efeito do clima na cultura e na praga/doença. $\mathrm{O}$ objetivo deste estudo foi simular, concomitantemente, a partir da integração de um modelo de simulação da cultura da soja com modelos bioclimáticos dos organismos, o número de gerações de um inseto e seu parasitoide e a severidade de uma doença da soja em cenários que consideram diferentes momentos de ocorrência dos organismos/ doença, datas de plantio e grupo de maturação da cultivar, para uma longa série temporal de dados meteorológicos em dois municípios do Estado do Rio Grande do Sul.

\section{MATERIAL E MÉTODOS}

Dados diários de radiação solar (MJ $\left.\mathrm{m}^{-2} \mathrm{dia}^{-1}\right)$, temperaturas máxima e mínima $\left({ }^{\circ} \mathrm{C}\right)$ e precipitação pluvial ( $\mathrm{mm}$ ) foram obtidos das estações do Instituto Nacional de Meteorologia dos municípios de Passo Fundo (latitude -28,263 e longitude -52,407) e Santa Rosa (latitude -27,871 e longitude -54,481), no RS. Esses representam duas importantes regiões produtoras de soja no Estado, com característica climática distinta e que se dispõe de registros de séries históricas de dados meteorológicos. As séries temporais utilizadas nas simulações continham 52 anos para Passo Fundo (safras de 1957/58 a 2008/09) e 34 anos para Santa Rosa (safras de 1975/76 a 2008/09). A suíte Decision Support System for Agrotechnology Transfer (DSSAT) foi usada para simular o desenvolvimento da cultura da soja com o modelo CROPGRO-Soybean (JONES et al., 2003) e estimar a data de determinados eventos fenológicos, a partir da qual foram rodados modelos bioclimáticos para a predição de eventos do ciclo 
biológico (número de gerações) de $\boldsymbol{E}$. heros e seu parasitoide $\boldsymbol{T}$. podisi e da severidade da ferrugem asiática da soja ao final do ciclo. Para os insetos, o cálculo do acúmulo térmico (graus-dia) e do número de gerações em cada data de semeadura e para cada grupo de maturação foram utilizadas as equações propostas por CIVIDANES (2000): quando o limite térmico inferior for menor que a temperatura mínima registrada no dia, $\mathrm{GD}=(\mathrm{Tmin}-\mathrm{Tb})+[(\mathrm{Tmax}-\mathrm{Tmin}) / 2]$, em que GD = graus-dia, Tmin = temperatura mínima do ar; Tmax = temperatura máxima do ar; $\mathrm{Tb}=$ temperatura base do inseto. Quando o limite térmico inferior for maior ou igual à temperatura mínima e menor do que a máxima, GD=(Tmax-Tb $)^{2} /[2 *(T \max -$ Tmin)]. Quando o limite térmico superior for maior que a temperatura máxima, não há graus-dia acima do limite térmico inferior. $\mathrm{O}$ número de gerações em determinado período $(\mathrm{NC})$ é dado por $\mathrm{NC}=\mathrm{GD}$ acumulado diário / $\mathrm{K}, \mathrm{K}=$ constante térmica. $\mathrm{A} \mathrm{Tb}$ e os GD foram $14,2^{\circ} \mathrm{C}$ e 327,8 graus-dia (COSTA, 1998; CIVIDANES \& PARRA, 1994) e $11,1^{\circ} \mathrm{C}$ e 205 graus-dia para $\boldsymbol{E}$. heros e $T$. podisi, respectivamente (TORRES et al., 1997; PACHECO \& CORRÊAFERREIRA, 2000). Para a ferrugem asiática, foi usado um modelo de regressão linear (DEL PONTE et al., 2006) que estima a severidade final (\%) da ferrugem asiática a partir da data de detecção da doença. $\mathrm{O}$ modelo é dado por $\mathrm{S}(\%)=-2,1433+(0,1811 * \mathrm{P} 30)+(1$, $\left.2865^{*} \mathrm{DP} 30\right)$, em que $\mathrm{S}(\%)$ é a severidade máxima, P30 é a precipitação acumulada em 30 dias após a data da detecção e DP30 é o número de dias de chuva no mesmo período. As cultivares utilizadas na simulação, com seus coeficientes genéticos constantes no pacote DSSAT, foram a Dom Mario, do grupo de maturação 5.5 (ciclo super-precoce), a Coodetec 202 do grupo 6.4 (ciclo precoce) e a Bragg do grupo 7 (ciclo normal). Foram avaliadas três datas de semeaduras espaçadas em 30 dias uma da outra, sendo: precoce (5 de outubro), recomendada para a região (5 de novembro) e tardia ( 5 de dezembro), conforme o zoneamento agrícola (MAPA, 2010). O modelo CROPGRO-Soybean simulou, para cada combinação (local $\mathrm{x}$ data de semeadura $\mathrm{x}$ grupo de maturação da soja), o número de dias da semeadura até determinados estádios fenológicos, bem como até a maturação fisiológica da soja para cada ano da série histórica (Figura 1). Aproximadamente 9000 simulações foram geradas a partir das variações

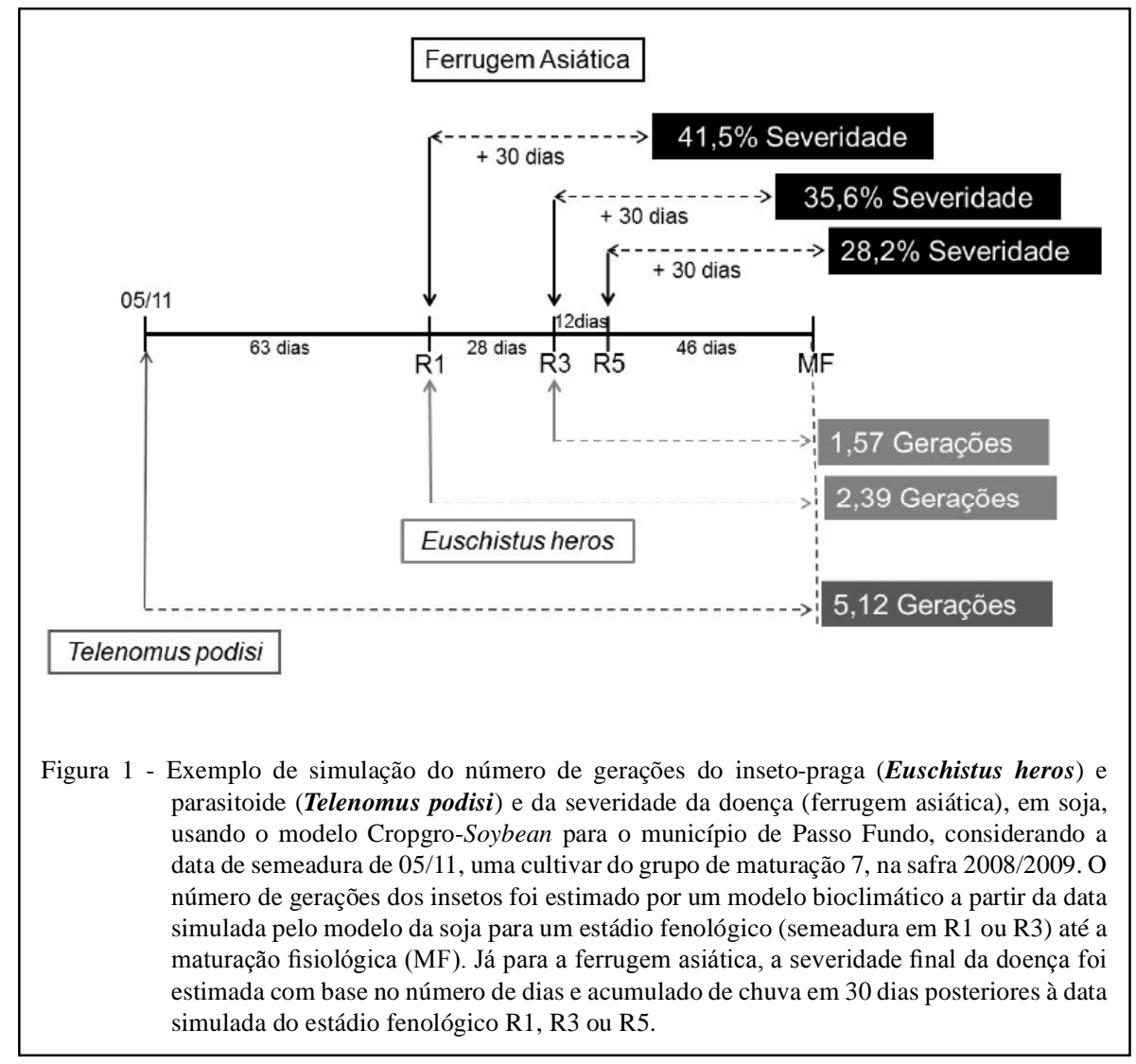

Ciência Rural, v.43, n.4, abr 2013. 
de data de plantio, grupo de maturação da cultivar e estádio fenológico de ocorrência da praga e da doença para os dois locais. Os eventos fenológicos simulados foram: início do florescimento (R1), início da formação das vagens (R3) e enchimento dos grãos (R5), somente para as simulações da ferrugem asiática. Para $\boldsymbol{E}$. heros, consideraram-se os estádios R1 e R3, sendo que, no MIP da soja, estes são os recomendados para avaliação e porque, embora os percevejos possam ocorrer mais tardiamente, nos estágios R4 e R5, a população não chega a aumentar em níveis que causem danos expressivos. Para $\boldsymbol{T}$. podisi, foi assumida a presença no local a partir da data da semeadura, considerando a presença de seus hospedeiros, sendo então simulado o número de gerações entre a semeadura e a maturação fisiológica. Os dados foram sumarizados em valores medianos, mínimos e máximos na série para o número de gerações dos insetos e severidade da doença.

\section{RESULTADOS E DISCUSSÃO}

Para E. heros, nos dois locais, o maior número de gerações foi simulado para semeaduras e ocorrência da praga em estádios mais precoces e no grupo mais tardio de maturação (Tabela 1). Comparando-se os locais, a média geral das medianas do número de gerações foi mais alta para Santa Rosa $(2,17)$ do que para Passo Fundo $(1,70)$, o que reflete as condições de temperaturas médias mais elevadas no primeiro local. Em Passo Fundo, o menor número de gerações (menor mediana 0,96 ) foi estimada em semeadura tardia de uma cultivar do grupo superprecoce e ocorrência em R3. Já a mediana máxima $(2,79)$, para o mesmo local, foi estimada em semeadura antecipada, ocorrência em estádio R1 e cultivar do grupo normal de maturação. Em Santa Rosa, a menor e maior mediana do número de gerações, 1,24 e 3,57, respectivamente, foram estimadas para as mesmas situações citadas para Passo Fundo. O aumento da incidência de $\boldsymbol{E}$. heros em algumas regiões brasileiras de clima tropical está relacionado com a melhor adaptação e temperaturas elevadas (CIVIDANES \& PARRA, 1994), o que fundamenta $\mathrm{o}$ fato de se ter simulado um maior potencial reprodutivo em Santa Rosa do que em Passo Fundo. Conforme CIVIDANES \& PARRA (1994), temperaturas de 26 a $28^{\circ} \mathrm{C}$ são as mais adequadas

Tabela 1 - Estimativa dos valores de mediana (mínimo e máximo) de gerações de Euschistus heros e de Telenomus podisi em soja, utilizando séries temporais de dados meteorológicos diários para o município de Passo Fundo (52 anos) e Santa Rosa (34 anos), RS.

\begin{tabular}{|c|c|c|c|c|c|c|}
\hline \multirow{2}{*}{\multicolumn{2}{|c|}{ Município }} & \multirow{2}{*}{ Data de semeadura } & \multirow{2}{*}{ Estádio de ocorrência } & \multicolumn{3}{|c|}{ - Grupo de maturação da cultivar--- } \\
\hline & & & & Grupo 5.5 (superprecoce) & Grupo 6.4 (precoce) & Grupo 7 (médio) \\
\hline \multirow{7}{*}{$\begin{array}{l}\text { Passo } \\
(\mathrm{n}=53)\end{array}$} & \multirow{7}{*}{ Fundo } & ..........- & $-E_{t}$ & ischistus heros------- & 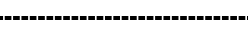 & 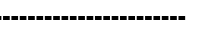 \\
\hline & & $05 /$ out & $\mathrm{R} 1$ & $1,88(1,51-2,16)$ & $2,28(1,87-2,62)$ & $2,78(2,39-3,17)$ \\
\hline & & $05 /$ out & $\mathrm{R} 3$ & $1,42(1,12-1,69)$ & $1,85(1,50-2,09)$ & $1,86(1,55-2,16)$ \\
\hline & & $05 /$ nov & $\mathrm{R} 1$ & $1,62(1,38-1,81)$ & $2,15(1,88-2,44)$ & $2,18(1,85-2,47)$ \\
\hline & & $05 /$ nov & R3 & $1,19(0,96-1,40)$ & $1,62(1,43-1,85)$ & $1,41(1,06-1,69)$ \\
\hline & & $05 / \mathrm{dez}$ & $\mathrm{R} 1$ & $1,32(1,02-1,53)$ & $1,85(1,59-2,08)$ & $1,74(1,43-2,13)$ \\
\hline & & $05 / \mathrm{dez}$ & $\mathrm{R} 3$ & $0,96(0,75-1,20)$ & $1,36(1,11-1,60)$ & $1,15(0,90-1,47)$ \\
\hline \multirow{6}{*}{$\begin{array}{l}\text { Santa } \\
(\mathrm{n}-30)\end{array}$} & \multirow{6}{*}{ Rosa } & $05 /$ out & R1 & $2,44(2,00-2,85)$ & $2,97(2,52-3,50)$ & $3,57(2,78-4,18)$ \\
\hline & & $05 /$ out & R3 & $1,85(1,45-2,14)$ & $2,41(1,99-2,88)$ & $2,35(1,48-2,89)$ \\
\hline & & $05 /$ nov & R1 & $2,04(1,51-2,37)$ & $2,80(2,47-3,20)$ & $2,81(1,58-3,45)$ \\
\hline & & $05 /$ nov & $\mathrm{R} 3$ & $1,47(0,98-1,78)$ & $2,13(1,68-2,43)$ & $1,80(0,55-2,37)$ \\
\hline & & $05 / \mathrm{dez}$ & $\mathrm{R} 1$ & $1,67(0,76-2,13)$ & $2,34(1,51-2,76)$ & $2,28(0,95-2,76)$ \\
\hline & & $05 / \mathrm{dez}$ & R3 & $1,24(0,29-1,55)$ & $1,72(0,95-2,20)$ & $1,50(0,17-1,94)$ \\
\hline \multirow{4}{*}{$\begin{array}{l}\text { Passo } \\
\left(\mathrm{n}^{-52}\right)\end{array}$} & & & 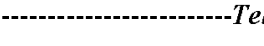 & nomus podisi----------- & & ------------------ \\
\hline & \multirow{3}{*}{ Fundo } & $05 /$ out & & $4,07(3,36-4,57)$ & $4,98(4,23-5,44)$ & $6,07(5,40-6,72)$ \\
\hline & & $05 /$ nov & & $3,52(3,07-3,82)$ & $4,68(4,25-5,17)$ & $4,84(4,15-5,36)$ \\
\hline & & $05 / \mathrm{dez}$ & & $2,92(2,33-3,29)$ & $4,02(3,52-4,46)$ & $3,95(3,35-4,61)$ \\
\hline \multirow{3}{*}{$\begin{array}{l}\text { Santa } \\
(n=34)\end{array}$} & \multirow{3}{*}{ Rosa } & 05/out & & $4,99(4,08-5,77)$ & $6,10(5,23-6,94)$ & $7,35(5,74-8,36)$ \\
\hline & & $05 /$ nov & & $4,23(3,11-4,80)$ & $5,74(5,07-6,31)$ & $5,77(3,25-6,94)$ \\
\hline & & $05 / \mathrm{dez}$ & & $3,46(1,55-4,28)$ & $4,84(3,11-5,56)$ & $4,76(1,96-5,61)$ \\
\hline
\end{tabular}


para a postura e desenvolvimento desses percevejos, podendo o número de gerações variar de três a seis, corroborando os dados encontrados no presente estudo para cenários de maior disponibilidade de tempo para o desenvolvimento da praga, no caso do plantio antecipado e cultivar de ciclo médio, sob temperaturas favoráveis. $\mathrm{O}$ fato de se ter menor número de gerações para plantios em dezembro, deve-se mais por se ter o ciclo da cultura encurtado e a praga menor tempo para se desenvolver. Esses resultados indicam que, para as safras de soja que sucedem anos de grandes infestações do percevejo, por exemplo, o plantio antecipado de uma cultivar do grupo de maturação mais precoce poderia minimizar o impacto do potencial reprodutivo das populações de E. heros na cultura. Segundo CORRÊA-FERREIRA (2005), um maior impacto dos percevejos é esperado quando estes ocorrem a partir do final do período vegetativo até o florescimento da soja, ressaltando a importância do monitoramento da cultura nesse período, como indica o MIP-soja (REUNIÃO, 2009).

Quanto ao efeito da época de semeadura, observou-se uma tendência de aumento no número de gerações de $\boldsymbol{E}$. heros na primeira data (05/10), diminuindo sucessivamente na data intermediária $(05 / 11)$ e tardia (05/12) nos dois municípios estudados (Tabela 1). Essa variação se dá em função de diferenças nas temperaturas médias, que são mais baixas nas primeiras datas. Em programas de MIP, as constantes térmicas dos insetos são associadas às temperaturas médias ambientais nas fases dos ciclos das culturas para determinar o potencial de injúria desses organismos sobre as plantas (PEDIGO, 1996). Estes parâmetros são usados para as tomadas de decisão a respeito do uso, ou não, de medidas de controle. No $\mathrm{RS}$, a semeadura é feita normalmente em novembro, sendo que a simulação indica que, na região, deve ocorrer de duas a três gerações da praga para a cultivar do grupo normal de maturação, e de uma a duas para aquelas dos grupos superprecoce e precoce.

Para as simulações de $\boldsymbol{T}$. podisi, seguindo a mesma tendência de seu hospedeiro, uma maior média geral das medianas do número de gerações foi estimada para Santa Rosa (5,24 gerações) do que para Passo Fundo (4,33 gerações). A menor mediana (2,92 gerações) foi para plantio tardio de uma cultivar de ciclo precoce em Passo Fundo, enquanto que a maior mediana foi de 7,35 gerações para plantio em outubro de uma cultivar do grupo normal de maturação. De maneira geral, houve tendência de diminuição no número de gerações com o retardo do plantio e uso de cultivar de um grupo mais precoce (Tabela 1).
Relatos da literatura mostram que as maiores taxas de parasitismo em ovos ocorrem nos meses de outubro a dezembro, com variação de 30 a $70 \%$ ao longo do ciclo da cultura (CORRÊA-FERREIRA \& PANIZZI, 1999). Entretanto, é importante ressaltar que o número de gerações do parasitoide está mais relacionado ao número de gerações do hospedeiro, neste caso, dos ovos. O fato de $\boldsymbol{E}$. heros ter apresentado em torno de 1 a 3,5 gerações, dependendo do local, enquanto que $\boldsymbol{T}$. podisi apresentou em torno de 4 a 6 gerações, sugere o potencial de controle da praga pelo percevejo. LENTEREN (2009) reforça a importância de que a razão intrínseca de aumento populacional do parasitoide deve ser igual ou superior a de seu hospedeiro, para que este seja considerado um agente eficiente de controle biológico. PREZOTTI \& PARRA (2002) também ressaltam que a sincronização sazonal com o hospedeiro, alto potencial reprodutivo e a boa resposta à densidade são critérios importantes na definição de inimigos naturais em programas de controle biológico. A liberação de um inimigo natural em condições de temperatura acima ou abaixo da faixa térmica considerada ótima para o desenvolvimento e a precipitação pluviométrica no momento da liberação podem afetar drasticamente sua sobrevivência em campo (PINTO \& PARRA, 2002). Os resultados da simulação mostram que os dois locais não apresentam limitações para o desenvolvimento do parasitoide, demonstrando o potencial do uso do controle biológico da praga na região.

Para a ferrugem asiática, os efeitos do grupo de maturação da cultivar, momento de detecção e data de semeadura da soja na severidade da doença foram pouco aparentes. Para Passo Fundo, as medianas na série histórica variaram entre 36 e $42 \%$, enquanto que, para Santa Rosa, variaram de 32 e $44 \%$ (Tabela 2). Em alguns anos, como em 2000, no município de Santa Rosa, para a data de plantio em 05/11, a severidade foi estimada em $80 \%$ na cultivar do grupo 5.5 e, em torno de $60 \%$, nas cultivares dos grupos 6.4 e 7 , quando a doença foi detectada em R1 (dados não mostrados). Se a ferrugem fosse detectada mais tardiamente, como em R3 ou R5, a severidade reduziria para $40 \%$ nos três grupos de maturação. Tal diferença se deve à variação intrasazonal dos padrões de precipitação pluvial, que podem ter períodos de estiagem alternados com períodos chuvosos. Assim, não se pode afirmar que há menor risco da doença em semeaduras precoces ou quando se utiliza cultivar de ciclo curto na região norte do RS já que as condições de chuva em uma determinada safra podem coincidir com os períodos 
Tabela 2 - Estimativa dos valores de mediana (mínimo e máximo) de severidade (\%) da ferrugem asiática da soja em função da época de semeadura, grupo de maturação e momento da detecção, utilizando séries temporais de dados meteorológicos diários para o município de Passo Fundo (52 anos) e Santa Rosa (34 anos), RS.

\begin{tabular}{|c|c|c|c|c|c|c|}
\hline \multirow{2}{*}{\multicolumn{2}{|c|}{ Município }} & \multirow{2}{*}{ Data de semeadura } & \multirow{2}{*}{ Estádio de ocorrência } & \multicolumn{3}{|c|}{ de maturação da cultivar- } \\
\hline & & & & Grupo 5.5 (super-precoce) & Grupo 6.4 (precoce) & Grupo 7 (médio) \\
\hline \multirow{9}{*}{$\begin{array}{l}\text { Passo } \\
(\mathrm{n}=52)\end{array}$} & \multirow{9}{*}{ Fundo } & $05 /$ out & R1 & $39,15(11,28-83,60)$ & $38,05(8,69-91,01)$ & $38,61(89,41-15,92)$ \\
\hline & & $05 /$ out & R3 & $39,36(3,69-90,88)$ & $39,90(15,28-5,37)$ & $39,37(9,27-100,00)$ \\
\hline & & $05 /$ out & R5 & $41,64(9,27-100,00)$ & $40,37(7,97-91,73)$ & $42,20(10,30-74,53)$ \\
\hline & & $05 /$ nov & R1 & $40,31(9,27-94,43)$ & $39,41(17,44-79,87)$ & $39,14(9,27-90,38)$ \\
\hline & & $05 /$ nov & $\mathrm{R} 3$ & $42,92(11,64-73,22)$ & $39,77(9,20-90,38)$ & $44,66(9,00-88,44)$ \\
\hline & & $05 /$ nov & R5 & $44,12(9,00-87,21)$ & $42,24(13,67-82,11)$ & $38,16(12,64-91,61)$ \\
\hline & & $05 / \mathrm{dez}$ & $\mathrm{R} 1$ & $44,92(10,30-87,21)$ & $38,95(9,27-94,43)$ & $45,41(12,33-87,35)$ \\
\hline & & $05 / \mathrm{dez}$ & R3 & $39,17(12,55-100)$ & $43,45(12,33-84,00)$ & $36,40(5,79-75,00)$ \\
\hline & & $05 / \mathrm{dez}$ & R5 & $36,40(5,79-76,98)$ & $39,70(12,55-99,38)$ & $34,54(9,99-74,83)$ \\
\hline \multirow{9}{*}{$\begin{array}{l}\text { Santa } \\
(n=34)\end{array}$} & \multirow{9}{*}{ Rosa } & $05 /$ out & R1 & $39,15(11,28-83,60)$ & $34,16(9,94-100,00)$ & $32,71(5,61-84,85)$ \\
\hline & & $05 /$ out & $\mathrm{R} 3$ & $39,36(3,69-90,88)$ & $38,56(2,04-89,41)$ & $34,52(2,69-97,76)$ \\
\hline & & $05 /$ out & R5 & $41,64(9,27-100,00)$ & $37,71(2,69-95,75)$ & $35,37(5,48-89,21)$ \\
\hline & & $05 /$ nov & R1 & $40,31(9,27-94,43)$ & $44,19(2,69-82,01)$ & $34,28(2,69-78,19)$ \\
\hline & & $05 / \mathrm{nov}$ & R3 & $42,92(11,64-73,22)$ & $41,38(15,28-79,71)$ & $36,33(3,76-80,68)$ \\
\hline & & $05 /$ nov & R5 & $44,12(9,00-87,21)$ & $39,59(7,60-84,23)$ & $32,11(12,62-97,98)$ \\
\hline & & $05 / \mathrm{dez}$ & R1 & $44,92(10,30-87,21)$ & $36,29(7,60-84,23)$ & $41,38(2,69-83,64)$ \\
\hline & & $05 / \mathrm{dez}$ & R3 & $39,17(12,55-100)$ & $34,72(12,62-79,71)$ & $31,42(6,71-80,70)$ \\
\hline & & $05 / \mathrm{dez}$ & R5 & $36,40(5,79-76,98)$ & $30,79(6,71-81,07)$ & $29,03(0,00-73,51)$ \\
\hline
\end{tabular}

críticos para o estabelecimento da doença, mesmo que seja em plantios antecipados. Nessa situação, um menor risco da doença pode ocorrer devido a uma condição de escape direcionada mais ao inóculo do que propriamente de condições meteorológicas que favorecem o desenvolvimento da doença, conforme demonstrado neste estudo. Considerando que a doença pode ocorrer desde o início do florescimento, este estudo contribui com novo conhecimento mostrando que não existem evidências de que práticas como o plantio antecipado e uso de cultivares de grupos mais precoces de maturação, ou mesmo a entrada mais tardia da doença, diminuem o risco da doença por escape das condições meteorológicas favoráveis. Em anos favoráveis, é maior o potencial de danos em produtividade e os custos com aplicação de fungicidas, independente da época de plantio e ciclo da cultivar, conforme já verificado na região desde que a ferrugem foi detectada nesta (YORINORI et al., 2005). Diferentemente do trabalho anterior (DEL PONTE et al., 2011), este estudo não utilizou uma data fixa com base no calendário para a ocorrência inicial doença, mas sim a data simulada pelo modelo da cultura, a qual pode variar de um ano para o outro em função da data de plantio e temperatura sazonal.

\section{CONCLUSÃO}

Nos dois locais estudados, representativos e contrastantes quanto a condições de temperatura em duas importantes regiões produtoras, as simulações indicam que, em semeaduras antecipadas de uma cultivar de grupo normal de maturação, a ocorrência de $\boldsymbol{E}$. heros, no final do estádio vegetativo, aumenta potencialmente o número de gerações da praga até a maturação fisiológica da soja, bem como do parasitoide T. podisi. Para a ferrugem asiática, não há evidências de que condições meteorológicas menos favoráveis à doença ocorram em função da antecipação do plantio antecipado e uso de cultivares de grupo maturação superprecoce.

\section{AGRADECIMENTOS}

Ao Conselho Nacional de Desenvolvimento Científico e Tecnológico (CNPq), pela concessão da bolsa de Mestrado, e ao João Eduardo Pedrini, pelo auxílio na programação das simulações.

\section{REFERÊNCIAS}

BATCHELOR, W.D. et al. Extending the use of crop models to study pest damage. Transactions of the Asae, v.36, p.551-558, 1993. 
CIVIDANES, F.J. Uso de graus-dia em entomologia, com particular referência ao controle de percevejos pragas da soja. Jaboticabal: Funep, 2000. 31p.

CIVIDANES, F.J.; PARRA, J.R.P. Biology in different temperatures and thermal requirements of stink bugs pests of soybean. Pesquisa Agropecuária Brasileira, v.29, n.12, p.18411846, 1994.

CORREAA-FERREIRA, B.S. Suscetibilidade da soja a percevejos na fase anterior ao desenvolvimento das vagens. Pesquisa Agropecuária Brasileira, v.40, n.11, p.1067-1072, 2005. Disponível em: <http://www.scielo.br/scielo.php?pid=S0100204X2005001100003\&script=sci_arttext $>$. Acesso em: $20 \mathrm{fev}$. 2011. doi: 10.1590/S0100-204X2005001100003.

CORREAA-FERREIRA, B.S. Trissolcus basalis para o controle de percevejos da soja. In: PARRA, J.R.P. et al. (Eds.). Controle biológico no Brasil: parasitoides e predadores. São Paulo: Manole, 2002. p.449-471.

CORRÊA-FERREIRA, B.S.; PANIZZI, A.R. Percevejos da soja e seu manejo. Londrina: Embrapa-CNPSo, 1999. 45p. (Circular Técnica 24).

COSTA, M.L.M. et al. Biologia reprodutiva de Euschistus heros (F.) (Heteroptera: Pentatomidae). Anais da Sociedade Entomológica do Brasil, v.27, p.559-568, 1998. Disponível em: <http://www.scielo. br/scielo.php?script=sci_arttext\&pid=S0301-80591998000400008>. Acesso em: 10 mar. 2011. doi: 10.1590/S0301-80591998000400008.

DEL PONTE, E.M. et al. A model-based assessment of the impacts of climate variability on Fusarium head blight seasonal risk in southern Brazil. Journal of Phytopathology, v.157, p.675-681, 2009. Disponível em: <http://dx.doi.org/10.1111 /j.1439-0434.2009.01559.x>. Acesso em: 05 jan. 2011. doi: 10.1111/j.1439-0434.2009.01559.x.

DEL PONTE, E.M. et al. Early-season warning of soybean rust regional epidemics using El Niño Southern/Oscillation information. International Journal of Biometeorology, v.55, p.375-383, 2011. Disponível em: <http://dx.doi.org/10.1007/s00484-010-0365-6>. Acesso em: 17 jan. 2011. doi: 10.1007/s00484-010-0365-6.

DEL PONTE, E.M. et al. Predicting severity of Asian soybean rust with empirical rainfall models. Phytopathology, v.96, p.797-803, 2006. Disponível em: <http://www6.ufrgs.br/agronomia/fitossan/ epidemiologia/wp-content/uploads/2009/09/2006-2delponte_sbr_ phytopathology.pdf>. Acesso em: 17 jan. 2008. doi: 10.1094/ PHYTO-96-0797.

DOETZER, A.K.; FOESTER, L.A. Desenvolvimento, longevidade e reprodução de Trissolcus basalis (Wollaston) e Telenomus podisi Ashmead (Hymenoptera: Scelionidae) em condições naturais durante a entressafra da soja no Sul do Paraná. Neotropical Entomology, v.36, n.2, p.233-242, 2007. Disponível em: <http://www.scielo.br/scielo.php?script=sci_arttext\&pid=S1519566X2007000200009>. Acesso em: 14 fev. 2011. doi: 10.1590/ S1519-566X2007000200009.

HOFFMAN-CAMPO, C.B. et al. Pragas da soja no Brasil e seu manejo integrado. Londrina: Embrapa Soja, 2000. 70p. (Circular Técnica 30).

INSTITUTO BRASILEIRO DE GEOGRAFIA E ESTATÍSTICA. Levantamento Sistemático da Produção Agrícola. Rio de Janeiro, 2010. V.21, n.6, p.1-80.
JONES, J.W. et al. The DSSAT cropping system model. European Journal of Agronomy, v.18, p.235-265, 2003. Disponível em: <http://www.uwyo.edu/plantsciences/afri-cap-legumeadoption/ files/pdfs/dssat.pdf>. Acesso em: 20 mar. 2011. doi: 10.1016/ S1161-0301(02)00107-7.

LENTEREN, J.C. Critérios de seleção de inimigos naturais. In: BUENO, V.X.P. Controle biológico de pragas: produção massal e controle de qualidade. 2.ed. Lavras: UFLA, 2009. 430p.

MEDEIROS, L.; MEGIER, G.A. Ocorrência e desempenho de Euschistus heros (F.) (Heteroptera: Pentatomidae) em plantas hospedeiras alternativas no Rio Grande do Sul. Neotropical Entomology, v.38, p.459-463, 2009. Disponível em: <http://www.scielo.br/scielo.php?pid=S1519566X2009000400003\&script=sci_abstract\&tlng=pt $>$. Acesso em: 16 maio, 2011. doi: 10.1590/S1519-566X2009000400003.

MINISTÉRIO DA AGRICULTURA, PECUÁRIA E ABASTECIMENTO. Disponível em: 〈http://www.mapa.gov.br>. Acesso em: 15 jan. 2011.

PACHECO, D.J.P. CORRÊA-FERREIRA, B. Parasitismo de Telenomus podisi Ashmead (Hymenoptera: Scelionidae) em populações de percevejos pragas da soja. Anais da Sociedade Entomológica do Brasil, v.29, n.2, p.295-302, 2000. Disponível em: <http://www.scielo.br/scielo.php?pid=S0301$80592000000200011 \&$ script $=$ sci_arttext $>$. Acesso em: 18 mar. 2011. doi: 10.1590/S0301-80592000000200011.

PANIZZI, A.R. et al. Bioecologia e danos de percevejos-pragas da soja. In: EMBRAPA. Resultados de pesquisa da Embrapa Soja 1998. Londrina: Embrapa Soja, 1999. 247p. (Embrapa Soja. Documentos, 125).

PANIZZI, A.R.; NIVA, C.C. Overwintering strategy of the brown stink bug in northern Paraná. Pesquisa Agropecuária Brasileira, v.29, p.509-511, 1994.

PEDIGO, L.P. Entomology \& pest management. New Jersey: Pretice Hall, 1996. 679p.

PINTO, A. de S.; PARRA, J.P. Liberação de inimigos naturais. In: PARRA, J.P. et al. Controle biológico no Brasil: parasitoides e predadores. São Paulo: Manole, 2002. p.325-342.

PREZZOTI, L.; PARRA, J.R. Controle de qualidade em criações massais de parasitóides e predadores. In: PARRA, J.R. et al. Controle biológico no Brasil: parasitóides e predadores. São Paulo: Manole, 2002. p.295-312.

REUNIÃO DE PESQUISA DA SOJA DA REGIÃO SUL, 37. Indicações técnicas para a cultura da soja no Rio Grande do Sul e em Santa Catarina 2009/2010. Porto Alegre: Universidade Federal do Rio Grande do Sul, 2009. 144p.

ROSSI, V. Modeling plant diseases for decision making in crop protection. In: OERKE, E.C. et al. Precision crop protection - the challenge and use of heterogeneity. Netherlands: Spring, 2010. p.241-258.

STINNER, R.E. et al. Simulation of temperature-dependent development in population dynamics models. Canadian Entomology, v.107, p.1167-1174, 1975.

TORRES, J.B. et al. Exigências térmicas e potencial de desenvolvimento dos parasitóides Telenomus podisi Ashmead 
e Trissolcus brochymenae (Ashmead) em ovos do percevejo predador Podisus nigrispinus (Dallas). Anais da Sociedade Entomológica do Brasil, v.26, n.3, p.445-453, 1997. Disponível em: <http://www.scielo.br/scielo.php?pid=S0301$80591997000300006 \&$ script=sci arttext $>$. Acesso em: 20 fev. 2011. doi: 10.1590/S0301-80591997000300006.
YORINORI, J.T. et al. Epidemics of soybean rust (Phakopsora pachyrhizi) in Brazil and Paraguay from 2001 to 2003. Plant Disease, v.89, p.675-677, 2005. Disponível em: <http:// apsjournals.apsnet.org/doi/pdf/10.1094/PD-89-0675>. Acesso em: 13 jan. 2011. doi: 10.1094/PD-89-0675. 